\title{
Mechanical, Barrier, Adhesion and Antibacterial Properties of Pullulan / Graphene Bio Nanocomposite Coating on Spray Coated Nanocellulose Film for Food Packaging Applications
}

Ragavanantham Shanmugam

Navajo Technical University

Vishnuvarthanan Mayakrishnan ( $\nabla$ vishnuvarthanan.india@gmail.com )

Anna University Chennai https://orcid.org/0000-0002-7821-2471

\section{Radhakrishnan Kesavan}

Central Institute of Technology Kokrajhar

Kirubanandan Shanmugam

University of Madras

Subha Veeramani

University of Madras

Rajangam llangovan

University of Madras

\section{Research Article}

Keywords: Nanocellulose, Pullulan, Graphene, Coating, Adhesion Strength, Antibacterial

Posted Date: July 26th, 2021

DOl: https://doi.org/10.21203/rs.3.rs-660354/v1

License: (c) (i) This work is licensed under a Creative Commons Attribution 4.0 International License. Read Full License

Version of Record: A version of this preprint was published at Journal of Polymers and the Environment on October 15th, 2021. See the published version at https://doi.org/10.1007/s10924-021-02311-2. 


\section{Abstract}

In this study, an environmentally friendly and biodegradable pullulan/graphene bio nanocomposite was prepared and coated on the nanocellulose film to improve the surface, mechanical, barrier and antibacterial properties. The nanocellulose films were prepared by using a spray coating of nanocellulose suspension on stainless steel plates. The graphene nanoparticles were prepared by the modified Hummers method. The pullulan/graphene bio nanocomposites were prepared by solvent method with the addition of various wt $\%(0,0.05,0.1,0.2)$ of graphene with pullulan. The coating was carried out by the roller coating method. Results showed that the increased graphene nanoparticles in pullulan coating increased the opacity, surface hydrophobicity, tensile strength, oxygen transmission rate and watervapour transmission rate of the coated nanocellulose film. Also, the coated film showed excellent antibacterial properties against both gram-negative E.coli and gram-positive S.aureus. In this research work, it was concluded that the graphene nanoparticles of $0.2 \mathrm{wt} \%$ showed efficient results. The exceptional properties of the pullulan/graphene bio nanocomposite coating on the nanocellulose film will give a new pathway to high performance food packaging applications.

\section{Introduction}

Nowadays, awareness about the environment and moving towards sustainable and bio-based materials has created the view from conventional synthetic resources to profuse, inexpensive and biodegradable substitutes [1]. Because of environmental pollution and deficiency of resources had restricted the packaging materials growth, researchers started to look around bio-based materials [2]. But it is a big challenge to prepare new biodegradable polymer composite films for packaging to solve the problem of waste disposal [3]. Several biobased packaging materials such as cellulose, chitosan, pectin, starch and their bio derivatives are used. Among them, cellulose-based packaging materials are widely used because of their abundance, renewable character, biocompatibility, biodegradability and other specific properties [4]. In particular, nanocellulose has gained much attention in the past few years because of its massive capabilities in various applications such as food packaging, biomedical, fibers, adhesives and automotive applications [5].

Nanocellulose is a biodegradable, renewable nanomaterial and it is available in large quantities. It has outstanding various properties such as specific strength, thermal stability and effortless chemical functionalization [6]. Nanocellulose is being used as coating or film in bio-based food packaging applications because of low cost, non-toxicity, biodegradability, renewability and high barrier property for gas [7]. Nanocellulose film will be a good alternative packaging material that has some limitations in mechanical, watervapour barrier, wettability and antibacterial properties. Several efforts have been made to resolve the limitations by blending in cellulose or coating on cellulose films to increase the usage of nanocellulose in food packaging applications. Vesna [8] studied the effect of dextran coated silver nanoparticles in nanocellulose in the barrier and antimicrobial properties for food packaging applications. Dehnad et al.[9] extended the ground meat shelf life by chitosan and nanocellulose biocomposites. 
In the past few years, the research of pullulan has attracted much more attention of researchers. Pullulan is a non-ionic exopolysaccharide attained from the fungus-like yeast Aureobasidium pullulans fermentation medium. It is a biodegradable, low cost, non-toxic, eco friendly, biocompatible, noncarcinogenic, non-mutagenic and edible water-soluble biopolymer [10]. It is used in various applications especially in food packaging as films and coatings because it is colourless, odourless, tasteless, heat sealable and transparent ${ }^{7}$. However, to use a biopolymer as a food packaging material it should have required functional properties such as mechanical, barrier and antibacterial. Natural pullulan has limited mechanical and barrier properties and it does not possess antibacterial properties which have restricted to use in food packaging applications. The best solution is to add various nanoparticles to pullulan and to increase the functional properties [11]. Liu et al. [12] investigated the effect of nano $\mathrm{TiO}_{2}$ in the physical, mechanical properties of pullulan film and found that the tensile strength and watervapour permeability of the film was $15 \mathrm{MPa}$ and $6.6 \times 10^{-4} \mathrm{gm} / \mathrm{m}^{2} \mathrm{~h} \mathrm{KPa}$.

In recent years, the rapid development of nanomaterials has shown new opportunities in food packaging applications [13]. Graphene is a single atom thick sheet of carbon with $\mathrm{sp}^{2}$ hybridization and it is organized in a honeycomb lattice. Due to its outstanding properties, graphene is a rising star in materials science [14]. It possesses high surface area, greater mechanical and barrier properties and also good antibacterial properties [15]. It has various functional groups such as hydroxyl, epoxyl and carboxyl in the structure. It is an effective reinforcement for the improvement of polymer properties because of proper dispersion and better interaction with the polymer matrix. The use of graphene is of great interest in food packaging applications because it enhanced its properties and therefore considered a very promising material. There are no scientific reports on the biodegradable pullulan based graphene bio nanocomposite coating on nano cellulose film in the background of food packaging applications.

The objective of this study was to prepare pullulan/graphene bio nanocomposites and to coat on the nano cellulose film. The effect of coating on nano cellulose film was investigated against contact angle, opacity, tensile, barrier, adhesion and antibacterial properties. This research work can be a valuable directive for improving the research of new green packaging material.

\section{Materials And Methods}

\section{Materials}

The nomenclature for nanocellulose has not been reported consistently in the previous scientific investigations. It is also called micro fibrillated cellulose (MFC), nano-fibrils, micro-fibrils and nanofibrillated cellulose (NFC) / nanocellulose (NC). Nanocellulose (NC) supplied from DAICEL Chemical Industries Limited (Celish KY-100S) was used to prepare films. NC sample was used at consistencies ranging from 1.0 to $2.0 \mathrm{wt}$. \%, prepared by diluting the original concentration of $25 \mathrm{wt}$. \% with distilled water and mixing for 15,000 revolutions in a disintegrator. The average diameter of cellulose nanofibrils in Celish KY-100S is reported to be $\sim 70 \mathrm{~nm}$ and a mean length of fibre is evaluated to be $8 \mu \mathrm{m}$ and an aspect ratio of $142 \pm 28$ [16]. 
Pullulan powder (98\%) of $\mathrm{Mw}-2.72 \times 10^{5} \mathrm{~g} / \mathrm{mol}$ was purchased from SRL Chemicals, India and glycerol (99.5\%) were purchased from Sigma Aldrich, India. Graphite powder (99.98\%) was bought from Sigma Aldrich, India. Fuming nitric acid (64\%), potassium permanganate (98\%), hydrochloric acid $(99.99 \%)$ sulphuric acid (99.99\%), hydrogen peroxide (98\%), sodium nitrate $(99.99 \%)$ was obtained from SRL Chemicals, India.

\section{Preparation of Nanocellulose film}

The nanocellulose (NC) film was prepared through spray coating as reported for the preparation of pure nanocellulose film. In this method, NC suspension was sprayed on the stainless steel plate on a moving conveyor which has a velocity of $1.25 \pm 0.25 \mathrm{~cm} / \mathrm{sec}$. The professional spray system Graco was used for spraying suspension at a discharge pressure of 200 bar. In the spray system, an elliptical spray jet with an angle of $52^{\circ}$ from the spray nozzle 52 has coverage of $21 \mathrm{~cm}$ suspension on the base surface. The distance from the spray nozzle to the square stainless steel plate was $45 \pm 1 \mathrm{~cm}$. The steady-state in the spray coating experimental set-up was allowed to run the system for 30 seconds to avoid any discontinuity in the spray jet. The wet spray coated composite film on the stainless steel plate was dried under standard laboratory conditions at 12 hours. The dried film was peeled from the stainless steel plate for evaluating their barrier performance and strength.

\section{Preparation of Graphene}

Graphene nanopowder was synthesized by the exfoliation process of graphite. According to the modified Hummers method, graphene oxide was synthesized by the oxidation process of natural pristine graphite. The appropriate amount of graphite powder and sodium nitrate was dissolved in $75 \mathrm{~mL}$ of sulphuric acid. The reaction temperature was maintained below $20^{\circ} \mathrm{C}$. Then, $10 \mathrm{~g}$ of potassium permanganate was added slowly to the solution over 1 hour. Then the mixture is stirred for $45 \mathrm{~min}$ at $40 \pm 2^{\circ} \mathrm{C}$. After the mixture was cooled to room temperature, $100 \mathrm{~mL}$ of deionized water was slowly added to the mixture to obtain a yellowish suspension. To remove the permanganate ions, $25 \mathrm{~mL}$ of hydrogen peroxide and 300 $\mathrm{mL}$ of deionized water solution was added to the mixture. The solution was filtered and washed with $10 \%$ of $\mathrm{HCl}$ aqueous solution for the removal of sulphate ions. To obtain the graphene powder, the filtration powder was exfoliated.

\section{Preparation of Pullulan/graphene bio nanocomposites}

Graphene with different concentrations $(0,0.05,0.1,0.2 \mathrm{wt} \%)$ was dispersed in distilled water $(5 \mathrm{~mL})$ at room temperature in an ultrasonic bath for $45 \mathrm{~min}$ to get a homogeneous dispersion. Pullulan solution (6 $\mathrm{wt} \%)$ were prepared by dissolving pullulan in glycerol aqueous solution $(10 \% \mathrm{w} / \mathrm{v})$ at ambient temperature. Then the pullulan solution was mixed with different amounts of prepared graphene solution. By mechanical stirring, the prepared mixtures were homogenized for 2 hours and sonicated for $30 \mathrm{~min}$ at room temperature. The prepared pullulan bio nanocomposite samples with various wt\% $(0,0.05,0.1,0.2)$ of graphene were designated as PG0, PG1, PG2, PG3 respectively.

\section{Film Coating}


According to the standard of ASTM D823-95(2001), the bio nanocomposite coatings on the nanocellulose films were carried out by $\mathrm{K}$ control coater according to with a constant speed of 150 $\mathrm{mm} / \mathrm{min}$. Then the coated films were dried at room temperature for 48 hours.

\section{Coating Thickness Measurement}

The thickness of nanocellulose film and pullulan/graphene bio nanocomposite coated films was measured using a digital micrometer (Mitutoyo, Japan) with an accuracy of $0.001 \mu \mathrm{m}$. The thickness was measured at various locations of the coated film for five times and the average value was calculated.

\section{Surface Colour}

The surface colour of the films was measured by spectrophotometer (X-Rite 528). The surface colour ( $L=$ $94.50, a=-1.22, b=-0.24)$ of nanocellulose film was used as a standard colour and the analysis was performed according to the standard of ASTM D2244. The $L^{*}, a^{*}, b^{*}$ was calculated by taking five values from each sample at different places and the average value was calculated. The total colour difference $(\Delta \mathrm{E})$ was calculated by using the following equation.

$\Delta \mathrm{E}=\left[(\Delta \mathrm{L})^{2}+(\Delta \mathrm{a})^{2}+(\Delta \mathrm{b})^{2}\right]^{0.5}(1)$

where $\Delta \mathrm{L}, \Delta \mathrm{a}$ and $\Delta \mathrm{b}$ are the difference between each colour value of the standard colour and the coated films.

\section{Opacity}

According to the ASTM E284 standard, the opacity of the nanocellulose and the coated films were determined by a Spectrophotometer (X-Rite 528). The opacity is expressed by the ratio of the film reflectance factor $\left(R_{b s}\right)$ which is backed by a black surface to the reflectance factor $\left(R_{w s}\right)$ backed by a white surface. The opacity of the films was expressed in \%.

\section{Contact angle}

The water contact angle of the bio nanocomposite coated cellulose films were investigated with a goniometer (Holmarc) by the sessile drop method at $23^{\circ} \mathrm{C}$ and $50 \% \mathrm{RH}$. The contact angle was measured by placing a $1 \mu \mathrm{L}$ droplet of water on the coated surface and captured the droplet image within $5 \mathrm{~s}$. The contact angle measurements were taken at five places on the film and the mean value was calculated. The uncertainty of the experiment was within $\pm 1^{\circ}$.

\section{Coating Adhesion Strength}

The T - peel strength test of standard ASTM D1876-93 was followed to find the coating adhesion strength of the samples. The $3 \mathrm{M}$ double-sided scotch tape was used and the strength was analysed by Universal Testing Machine (UTM, H10KS, Tinius Olsen, UK) at $23^{\circ} \mathrm{C}$ and $50 \% \mathrm{RH}$. The test was carried out at a rate of $10 \mathrm{~mm} / \mathrm{min}$. The experiment was carried out five times and the mean value was calculated.

\section{Tensile Strength}


The tensile strength of the coated films was carried out according to the standard of ASTM D882 by Universal Testing Machine (UTM, H10KS, Tinius Olsen, UK) at $23^{\circ} \mathrm{C}$ and $50 \% \mathrm{RH}$. The dimension of the coated sample used for analysis was $150 \times 25 \mathrm{~mm}$ with a gauge length of $25 \mathrm{~mm}$ at a rate of 10 $\mathrm{mm} / \mathrm{min}$. The tensile strength was carried out for five times and the average value was calculated. The final tensile strength was expressed in MPa.

\section{Oxygen Transmission Rate}

By using the standard of ASTM D3985, the oxygen transmission rate (OTR) for the coated films was calculated by Noselab ATS at $23^{\circ} \mathrm{C}$ and $50 \% \mathrm{RH}$. The machine pressure was $1 \mathrm{~atm}$. The value was taken at five different places of the coated samples and the mean value was calculated. All the samples were conditioned at ambient conditions.

\section{Watervapour Transmission Rate}

The WVTR of the samples were calculated according to the standard of ASTM F1249-90 by LyssyL805000 under the condition of $100 \% \mathrm{RH}$ at $23^{\circ} \mathrm{C}$. The test was repeated for five times and the mean average value was calculated.

\section{Antibacterial Properties}

The antibacterial properties of the pullulan/graphene bio nanocomposite coating on nano cellulose film were investigated by the colony count method. According to the standard of ASTM E 2149-01, under dynamic contact conditions, the coated film was tested against both gram-negative E.coli and grampositive S.aureus. A broth solution was prepared in $100 \mathrm{~mL}$ of water by blending the beef extract $(1 \mathrm{~g})$ and peptone $(2 \mathrm{~g})$. At $40^{\circ} \mathrm{C}$, the blended mixture was cultured for $24 \mathrm{hrs}$ at a speed of $200 \mathrm{rpm}$ in a shaking incubator. Using the $0.90 \%$ sterile $\mathrm{NaCl}$ aqueous solution, the cell suspension of the microorganism was diluted by a factor of $10^{6}$ for E.coli and S.aureus. The pullulan/graphene coated NC film samples were cut precisely in the dimension of $3 \mathrm{~cm} \times 3 \mathrm{~cm}$ and added into the cell suspension. Under the controlled temperature of $40^{\circ} \mathrm{C}$, it was shaken at a speed of $150 \mathrm{rpm}$ by shaking the incubator. After the incubation time of $6 \mathrm{hrs}, 100 \mu \mathrm{L}$ of suspension was dipped and spread on the petri dish which had sterilized nutrient agar. After the incubation, the growth of bacteria was visualized at $40^{\circ} \mathrm{C}$ for $24 \mathrm{hrs}$.

\section{Results And Discussion}

\section{Coating thickness}

The thickness of the pullulan/graphene based bio nanocomposite coating on nano cellulose film with various proportions is shown in Table 1. The addition of graphene in pullulan did not make any major change in the coating thickness. A slight variation of thickness was obtained for all the samples and it was normalized to $24 \mu \mathrm{m}$. The normalized thickness of $24 \mu \mathrm{m}$ was used for all the characterization and testing of films.

\section{Surface Colour}


The surface colour of the films is most important in terms of appearance because it directly influences the acceptance of customer [17]. The surface colour values of pullulan/graphene based bio nanocomposite coating on nano cellulose film with various concentrations are shown in Table 2.

The $L^{*}$ (whiteness), $a^{*}$ (red to green), $b^{*}$ (yellow to blue) values of nanocellulose film were $71.46,-0.39$ and 0.35 . After the pullulan coating in NC film, the $L^{*}, b^{*}$ value reduced to $69.84,0.11$ and $a^{*}$ value increased to 0.09 . After the inclusion of $0.05 \mathrm{wt} \%$ of graphene, the $L^{*}$ was significantly reduced to 32.95 and the $a^{*}, b^{*}$ value increased to $0.22,0.88$. Similarly, the $L^{*}$ reduction of $28.63,26.14$ and the increase of $a^{*}$ and $b *$ to $0.28,0.31$ and $0.92,0.99$ was obtained for $0.1 \mathrm{wt} \%$ and $0.2 \mathrm{wt} \%$. Likewise, the colour difference also got increased. The results clearly show that the graphene coating in NC film greatly influences the surface colour and colour difference of the films. It improved the light barrier properties of the material and blocked UV light transmission [18]. The degree of colour change was increased at higher graphene content. The surface colour of the packaging films was greatly dependent on the type of nanofillers used [19].

\section{Opacity}

The opacity of pullulan/graphene bio nanocomposite coating on the nanocellulose film was determined and it is shown in Fig.1.

The opacity for pure nano cellulose film was $16.9 \%$. After the pullulan coating in NC film, the opacity was increased to $17.8 \%$. Similarly, the value was increased to $22.5 \%$ by the incorporation of $0.05 \mathrm{wt} \%$ of graphene in pullulan. After the addition of $0.1 \mathrm{wt} \%$ of graphene, the opacity value was increased to $24.2 \%$ and the maximum opacity value of $29.9 \%$ was attained for $0.2 \mathrm{wt} \%$ of graphene in pullulan coating. This result shows that the opacity value got increased with an increase in graphene content in pullulan. This indicates that the graphene has been mixed well with pullulan and completely dispersed between the polymer matrices at a very low concentration [20]. It is commonly noticed with well developed exfoliated nanocomposites [21]. The exfoliation allowed for improved interaction between the pullulan and graphene [22]. Also, there was a strong scattering of graphene in pullulan increasing the opacity of UV visible light [23]. The opacity of the films provides extra information of dispersed particle size in the polymer matrix. The reinforced particle sizes are larger than the visible wavelength would block the light and leads to opaque films [24]. The opacity is a desirable property in packaging material intended to be used for food packaging applications.

\section{Contact angle analysis}

The contact angle is a measure of surface wettability and to identify whether it is hydrophobic or hydrophilic. The surface contact angle which is less than $65^{\circ}$ is identified as hydrophilic [25]. The contact angle of pullulan/graphene bio nanocomposite coating on the nanocellulose film was determined and it is shown in Fig. 2. 
The contact angle value of nano cellulose film was $42.2^{\circ}$. After the coating of pullulan in NC film, the contact angle value was increased to $68.6^{\circ}$. This shows the hydrophobic nature of the pullulan film. After the incorporation of $0.05 \mathrm{wt} \%$ of graphene in pullulan, the contact angle value was still increased to $70.8^{\circ}$. Similarly, for 0.1 and $0.2 \mathrm{wt} \%$ of graphene in pullulan, the contact angle value was increased to $73.4^{\circ}$ and $75.5^{\circ}$. This result shows that the graphene is hydrophobic and the contact angle value of coating was increased by the addition of graphene. The hydrophobic nature of graphene was due to the density functional theory. As compared to the adsorption energies on the surface of graphene the binding energy between the molecules of water is large. This cause the water molecules to form clusters on the surface [26]. Also, the other aspects such as the amount of loading, compatibility and the polymer matrix play a major role in hydrophobicity.

\section{Coating adhesion Strength}

The coating strength is the most important property to characterize the adhesion behaviour of and evaluating the quality of any coated material[27]. The $T$ - peel strength of the pullulan/graphene bio nanocomposite coating on the nanocellulose film was determined and it is shown in Fig. 3.

The adhesion strength of the uncoated nanocellulose was $3.61 \mathrm{~N} / \mathrm{cm}$. After the pullulan coating, the value was increased to $3.89 \mathrm{~N} / \mathrm{cm}$. Consequently, the adhesion strength was increased to $5.6 \mathrm{~N} / \mathrm{cm}$ after the incorporation of $0.05 \mathrm{wt} \%$ of graphene in pullulan. Similarly, the value was increased to $6.3 \mathrm{~N} / \mathrm{cm}$ for $0.1 \mathrm{wt} \%$ of graphene. A maximum of $7.9 \mathrm{~N} / \mathrm{cm}$ was attained for $0.2 \mathrm{wt} \%$ of graphene incorporated pullulan coating. The results showed that the adhesion strength value was increased by the addition of graphene. This was due to the surface roughness and surface energy of the nanocellulose film and these both were the main key factor for the increase in adhesion. Moreover, the addition of graphene in pullulan showed a significant effect on adhesion strength. The reinforced graphene in pullulan made the mechanical interlocking of the biopolymer matrix into the pores, cavities and asperities of the nanocellulose surface and made the adhesion strength increase [28].

\section{Tensile Strength}

Tensile strength is one of the most important parameters used to calculate the maximum stress that the material can withstand before breaking [29]. The tensile strength of the pullulan/graphene bio nanocomposite coating on the nanocellulose film was determined and it is shown in Fig. 4.

The tensile strength of the pure cellulose film was 7.4 MPa. After the coating of pullulan in the NC film, the tensile strength was increased to $8.9 \mathrm{MPa}$. The tensile strength was increased to $12.8 \mathrm{MPa}$ after the incorporation of $0.05 \mathrm{wt} \%$ of graphene in pullulan. Similarly, the tensile strength was increased to 15.7 and $19.9 \mathrm{MPa}$ for 0.1 and $0.2 \mathrm{wt} \%$ of graphene. These results showed that the tensile strength increases by an increase in graphene concentration. The increase in tensile strength was due to the exfoliated structure and the possible strain induces alignment of graphene in pullulan matrix [30]. It also confirmed the excellent compatibility between the pullulan and graphene [31]. The graphene could be efficiently used as the reinforcement in polymer composites which can provide good dispersion and improve the 
strengthening of the interface. Therefore, the force act on the pullulan/graphene may effectively be transferred to the graphene, results in a considerable increase in tensile strength [32]. The increase in tensile strength of the coated bio nanocomposite films was due to the physical attraction between the coating and NC film. The adhesion strength showed good results for the attraction between NC film and pullulan/graphene coating.

\section{Oxygen Transmission Rate:}

The oxygen transmission rate (OTR) of the pullulan and pullulan/graphene bio nanocomposite coating on the nanocellulose film was determined and it is shown in Fig. 5.

The OTR for the nanocellulose film was $1984.25 \mathrm{cc} / \mathrm{m}^{2}$.day.atm. After the pullulan coating on NC film, it was decreased to $1854.64 \mathrm{cc} / \mathrm{m}^{2}$.day.atm. Then the value was significantly reduced to 1120.56 $\mathrm{cc} / \mathrm{m}^{2}$.day.atm by the incorporation of $0.05 \mathrm{wt} \%$ of graphene. Similarly, the OTR value was still decreased to $987.47 \mathrm{cc} / \mathrm{m}^{2}$.day.atm for $0.1 \mathrm{wt} \%$ and the minimum value of $851.32 \mathrm{cc} / \mathrm{m}^{2}$.day.atm was achieved for $0.2 \mathrm{wt} \%$ for graphene. The mechanism for the increase in barrier property is usually due to the formation of a tortuous path against the gas molecules to cross through the film [33]. The orientation and highest exfoliation level of graphene in pullulan was also the reason decrease in OTR. The various factors to improve the barrier properties of the bio nanocomposite films are the effect of nanofiller, crystallization behaviour of the polymer nanocomposites and the interfacial interaction between the matrix and nanofillers [34]. Lee et al. [35] presented the lower barrier properties because of poor interfacial adhesion between PVC and GO nanocomposites. In this work, there was a large reduction in OTR after the addition of graphene in pullulan and it was due to the creation of a more tortuous path in the diffusing molecules and it can move around the impermeable fillers [36].

\section{Watervapour Transmission Rate}

The main aim of the food packaging material is to decrease the watervapour transfer between food and atmosphere and the WVTR should be low as possible [37]. The watervapour transmission rate (WVTR) of the pullulan and pullulan/graphene bio nanocomposite coating on the nanocellulose film was determined and it is shown in Fig. 6.

The WVTR for the pure nanocellulose film was $14.21 \mathrm{~g} / \mathrm{m}^{2}$.day. After the coating of pullulan in NC film, the WVTR value was decreased to $12.12 \mathrm{~g} / \mathrm{m}^{2}$. day. The WVTR value of the film was decreased to 8.3 $\mathrm{g} / \mathrm{m}^{2}$. day by the incorporation of $0.05 \mathrm{wt} \%$ of graphene. The WVTR value was still reduced by adding the $0.1 \mathrm{wt} \%$ of graphene in pullulan and the value was $6.1 \mathrm{~g} / \mathrm{m}^{2}$.day. The minimum value of $3.9 \mathrm{~g} / \mathrm{m}^{2}$.day was achieved for $0.2 \mathrm{wt} \%$ of graphene incorporated pullulan coating. From these results, it was noticed that the WVTR decreased by an increase in graphene in pullulan. The addition of graphene in pullulan is effectively improved the WVTR of the coating. These results might be attributed to the concept that the graphene was properly dispersed in the pullulan formed a tortuous path for transmission of watervapour and increased the effective path length of diffusion [38]. The hydrophobic behaviour of graphene was 
also the reason for the reduction in WVTR [39]. Also, the hydrogen bond formation between pullulan and graphene increased the force of adhesion made tougher for the water molecules to transmit through the film.

\section{Antibacterial Properties}

The pathogenic microorganisms and spoilage growth is the major reason for spoilage of food and reason for foodborne diseases [40]. Therefore, antibacterial activity is needed for food packaging. The antibacterial activity of the coated films was evaluated by the colony count method against gram-positive S. aureus and gram-negative E.coli. The total number of colonies was $100 \mathrm{CFU} / \mathrm{g}$ and the reason for the selection of S.aureus and E.coli was being the major microorganisms causing foodborne diseases to humans [41]. Fig. 7 presents the antibacterial activity of pullulan/graphene coating on nanocellulose film.

The nanocellulose film and pullulan did not show any antibacterial activity against both the microorganism. By the incorporation of $0.05 \mathrm{wt} \%$ of graphene in pullulan coating, the number of colonies was reduced to 73 for E.coli and 75 for S.aureus. Similarly, for $0.1 \mathrm{wt} \%$ of graphene, the colonies were still reduced to 61 for E.coli and 62 for S.aureus. The maximum reduction was obtained for $0.2 \mathrm{wt} \%$ of graphene and the values were 49 for E.coli and 51 for S.aureus. From these results, it was proved that graphene was responsible for the strong antibacterial activity and it reduces the growth of gram-negative bacteria and gram-positive bacteria. The possible antibacterial mechanisms of graphene are oxidative stress, wrapping isolation and stress of membrane [42]. In the oxidative stress mechanism, it involves various reactive oxygen species such as hydroxyl radical, hydrogen peroxide and superoxide radicals [43]. The membrane lipids, proteins and nucleic acid of bacteria were exposed to oxidative stress and it will be oxidized, degraded and lead to the destruction of cell [44]. In the wrapping isolation, the bacterial cells are enclosed in graphene and separated from the medium of growth. The graphene blocks the nutrients to pass through cell membranes and obstructs the growth [45]. In membrane stress, graphene nanoparticles destroy the bacteria by piercing the membrane and extract the phospholipids [46]. Finally, the addition of graphene in pullulan improved the antibacterial activity of the coated films.

\section{Conclusion}

In this study, a novel pullulan and graphene based bio nanocomposite was prepared and coated on the nano cellulose film. The functional properties of the coated nanocellulose film were investigated against coating thickness, surface colour, opacity, contact angle, adhesion strength, mechanical, barrier and antibacterial properties. From the results, the $0.2 \mathrm{wt} \%$ of graphene incorporated pullulan coating showed better properties than other concentrations. It showed good results in opacity and surface hydrophobicity. Also, the tensile, adhesion, oxygen and water vapour transmission properties of the coated films got increased. Finally, the antibacterial results showed that the pullulan/graphene bio nanocomposite coating restricted the growth of $E$. coli and $S$. aureus. This research will provide a new pathway for preparing environmentally friendly packaging films. 


\section{Declarations}

\section{Author Contributions}

Ragavanantham Shanmugam: Supervision; Vishnuvarthanan Mayakrishnan: Conceptualization - Writing - original draft - review \& editing; Radhakrishnan Kesavan: Formal analysis; Kirubanandan Shanmugam, Subha Veeramani: Data curation; Rajangam Ilangovan: Investigation; Validation

\section{Funding}

This research did not receive any specific grant from funding agencies in the public, commercial, or notfor-profit sectors.

\section{Compliance with Ethical Standards}

\section{Conflict of Interest}

The authors have no conflicts of interest to declare.

\section{Ethical Approval}

This article does not contain any studies with human participants or animals performed by any of the authors.

\section{Informed Consent}

It was obtained from all individual participants included in the study.

\section{References}

1. Chen S, Brahma S, Mackay J, Cao C, Aliakbarian B (2020) J Food Sci 85(3):517-525

2. Bailore NN, Balladka SK, Doddapaneni SJ, Mudiyaru MS (2021) J Polym Environ 29(4):1192-201

3. Kumar R, Rai B, Kumar G (2019) J Polym Environ 27(12):2963-73

4. Claro PI, Neto AR, Bibbo AC, Mattoso LH, Bastos MS, Marconcini JM (2016) J Polym Environ 24(4):363-71

5. Fukuzumi H, Saito T, Iwata T, Kumamoto Y, Isogai A (2009) Biomacromolecules 10(1):162-165

6. Shanmugam K, Varanasi S, Garnier G, Batchelor W (2017) Cellulose 24(7):2669-2676

7. Fukuya MN, Senoo K, Kotera M, Yoshimoto M, Sakata O (2014) Polymer 55(22):5843-6

8. Lazić V, Vivod V, Peršin Z, Stoiljković M, Ratnayake IS, Ahrenkiel PS, Nedeljković JM, Kokol V (2020) Food Packag Shelf Life 26:100575

9. Dehnad D, Mirzaei H, Emam-Djomeh Z, Jafari SM, Dadashi S (2014) carbohydr Polym 109:148-54

10. Silva NHCS, Vilela C, Almeida A, Marrucho IM, Freire CSR (2018) Food Hydrocoll 77:921-930 
11. Farris S, Unalan IU, Introzzi L, Fuentes-Alventosa JM, Cozzolino CA (2014) J Appl Polym Sci 31(13)

12. Liu Y, Liu Y, Han K, Cai Y, Ma M, Tong Q, Sheng L (2019) carbohydr Polym 218:95-102

13. Attia NF, Eid AM, Soliman MA, Nagy M (2018) J Polym Environ 26(3):1072-7.

14. Chen C-T, Chen K-I, Chiang H-H, Chen Y-K, Cheng K-C (2017) J Food Sci 82(1):108-117

15. Medeiros GS, Muñoz PA, de Oliveira CF, da Silva LC, Malhotra R, Gonçalves MC, Rosa V, Fechine GJ (2020) J Polym Environ 28(1):331-42

16. Le Lay G, Salomon E, De Padova P, Layet J-M, Angot T (2014) Aust J Chem 67(10):1370

17. Kosowska K, Domalik-Pyzik P, Nocuń M, Chłopek J (2018) Mater Chem Phys 216:28-36

18. Zhang X, Xiao G, Wang Y, Zhao Y, Su H, Tan T (2017) Carbohydr Polym169:101-107

19. Mehdikhani M, Gorbatikh L, Verpoest I, Lomov SV (2021) J Compos Mater 53(12):1579-669

20. Rhim J-W, Wang L-F (2014) Appl Clay Sci 97-98:174-181.

21. Vishnuvarthanan M, Rajeswari N (2019) Environ Chem Lett 17(1):439-445

22. Sinharay S, Bousmina M (2005) Prog Mater Sci 50(8):962-1079

23. Slavutsky AM, Bertuzzi MA, Armada M (2012) Braz J Food Technol 15(3):208-218

24. Martucci JF, Ruseckaite RA (2010) Polym Plast Technol Eng 49(6):581-588

25. Vishnuvarthanan M, Rajeswari N (2019) J Food Sci Technol 56(5):2545-2552

26. Ramji V, Vishnuvarthanan M (2020) Silicon https://doi.org/0.1007/s12633-020-00839-x

27. Pu J, Wan S, Lu Z, Zhang GA, Wang L, Zhang X, Xue (2013) J Mater Chem A Mater Energy Sustain 1(4):1254-1260

28. Pacaphol K, Aht-Ong D (2017) Surf Coat Technol 320:70-81.

29. Rhim J-W, Lee J-H, Hong S-I (2007) Packag Technol Sci 20(6):393-402

30. Rodriguez F, Sepulveda HM, Bruna J, Guarda A, Galotto MJ (2013) Packag Technol Sci 26(3):149160

31. Loryuenyong V, Saewong C, Aranchaiya C, Buasri A (2015) Packag Technol Sci 28(11):939-947

32. Trovatti E, Fernandes SCM, Rubatat L, da Silva Perez D, Freire CS, Silvestre AJ, Neto CP (2012) Compos Sci Technol 72(13):1556-1561.

33. Yang L, Li S, Zhou X, Liu J, Li Y, Yang M, Yuan Q, Zhang W (2019) Synth Met 253:122-130

34. Lim JW, Lim WS, Lee MH, Park HJ (2021) Packag Technol Sci 34(3):141-150

35. Lee KW, Chung JW, Kwak S-Y (2017) ACS Appl Mater Interfaces 9(38):33149-33158

36. Baele M, Vermeulen A, Leloup F, Adons D, Peeters R, Devlieghere F, De Meulenaer B, Ragaert P (2020) Packag Technol Sci 33(3):99-111

37. Wang H-S, Chen D, Chuai C-Z (2015) Packag Technol Sci 28(10):915-923

38. Javed A, Ullsten H, Järnström L (2017) Packag Technol Sci 30(8):399-410

39. Tabatabaei RH, Jafari SM, Mirzaei H, Nafchi AM, Dehnad D (2018) Int J Biol Macromol 111:1091-9 40. Farris S, Introzzi L, Piergiovanni L (2009) Packag Technol Sci 22(2):69-83 
41. Quintero RI, Rodriguez F, Bruna J, Guarda A, Galotto MJ (2013) Packag Technol Sci 26(5):249-265

42. Hennekinne J-A, De Buyser M-L, Dragacci S (2012) FEMS Microbiol Rev 36(4):815-836

43. Hegab HM, ElMekawy A, Zou L, Mulcahy D, Saint CP, Ginic-Markovic M (2016) Carbon 05:362-376

44. Zou X, Zhang L, Wang Z, Luo Y (2016) J Am Chem Soc 138(7):2064-2077

45. Gurunathan S, Han JW, Dayem AA, Eppakayala V, Kim J-H (2012) Int J Nanomedicine 7:5901-5914 46. Akhavan O, Ghaderi E, Esfandiar A (2011) J Phys Chem B 115(19):6279-6288

\section{Tables}

Table 1 Thickness of Pullulan/graphene bio nanocomposite coating

\begin{tabular}{|lll|}
\hline S. No. & Film Samples & $\begin{array}{l}\text { Thickness } \\
(\mu \mathrm{m})\end{array}$ \\
\hline 1. & NC & $46.03 \pm 0.02$ \\
\hline 2. & PG0 & $24.01 \pm 0.02$ \\
\hline 3. & PG1 & $24.03 \pm 0.01$ \\
\hline 4. & PG2 & \\
\hline 5. & PG3 & $24.02 \pm 0.02$ \\
\hline
\end{tabular}

Table 2 Surface colour of Pullulan/graphene bio nanocomposite coating 


\begin{tabular}{|llllll|}
\hline S. No. & Film Samples & $\mathrm{L}^{*}$ & $\mathbf{a}^{*}$ & $\mathbf{b}^{*}$ & $\Delta \mathrm{E}$ \\
\hline 1. & $\mathrm{NC}$ & 71.46 & -0.39 & 0.35 & 23.06 \\
\hline 2. & PG0 & 69.84 & 0.09 & 0.11 & 24.70 \\
& & & & & \\
\hline 3. & PG1 & 32.95 & 0.22 & 0.88 & 61.58 \\
& & & & & \\
\hline 4. & PG2 & 28.63 & 0.28 & 0.92 & 65.90 \\
& & & & & \\
\hline 5. & PG3 & 26.14 & 0.31 & 0.99 & 68.39 \\
& & & & & \\
\hline
\end{tabular}

Figures 


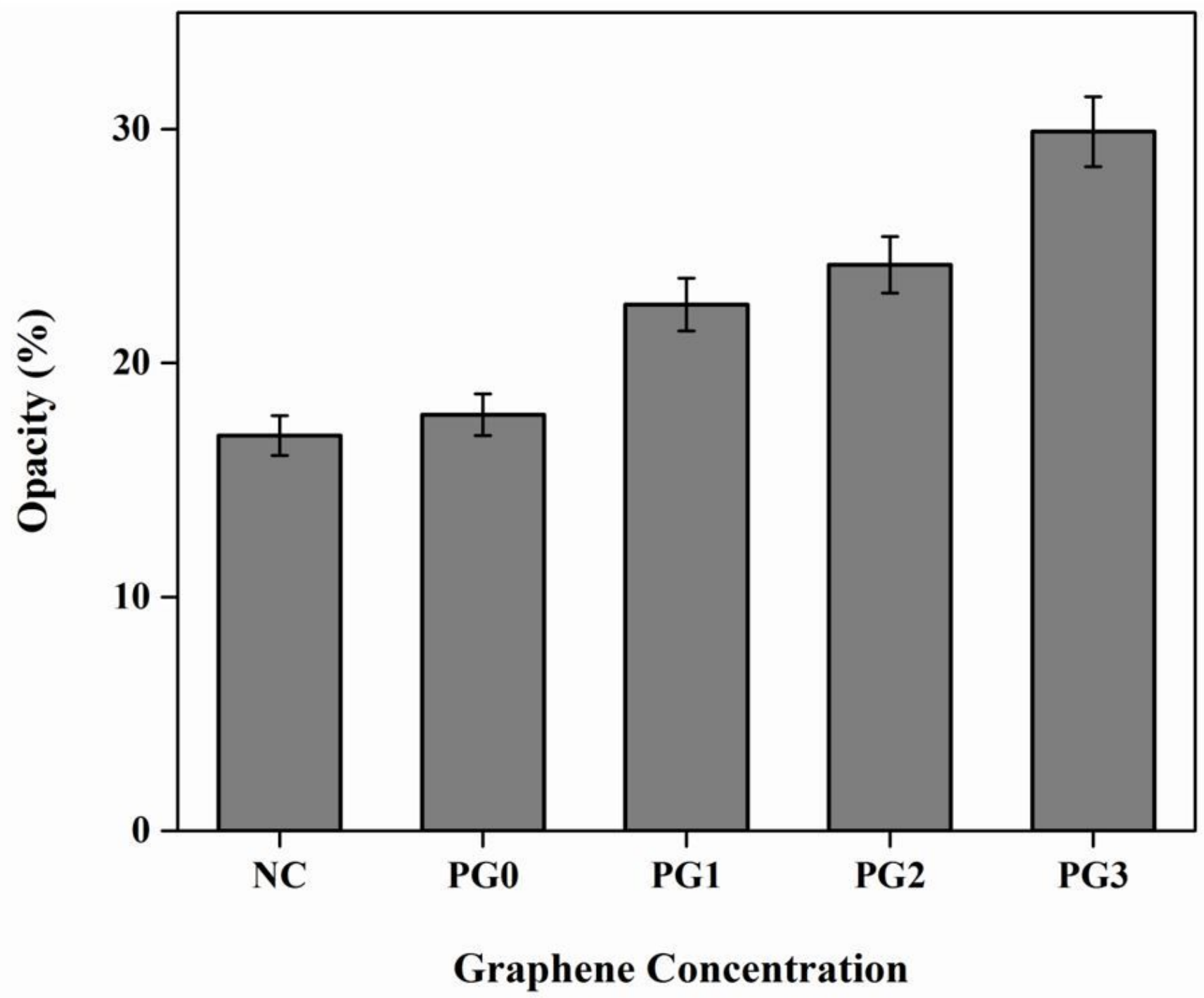

Figure 1

Opacity of Pullulan/graphene bio nanocomposite coating 


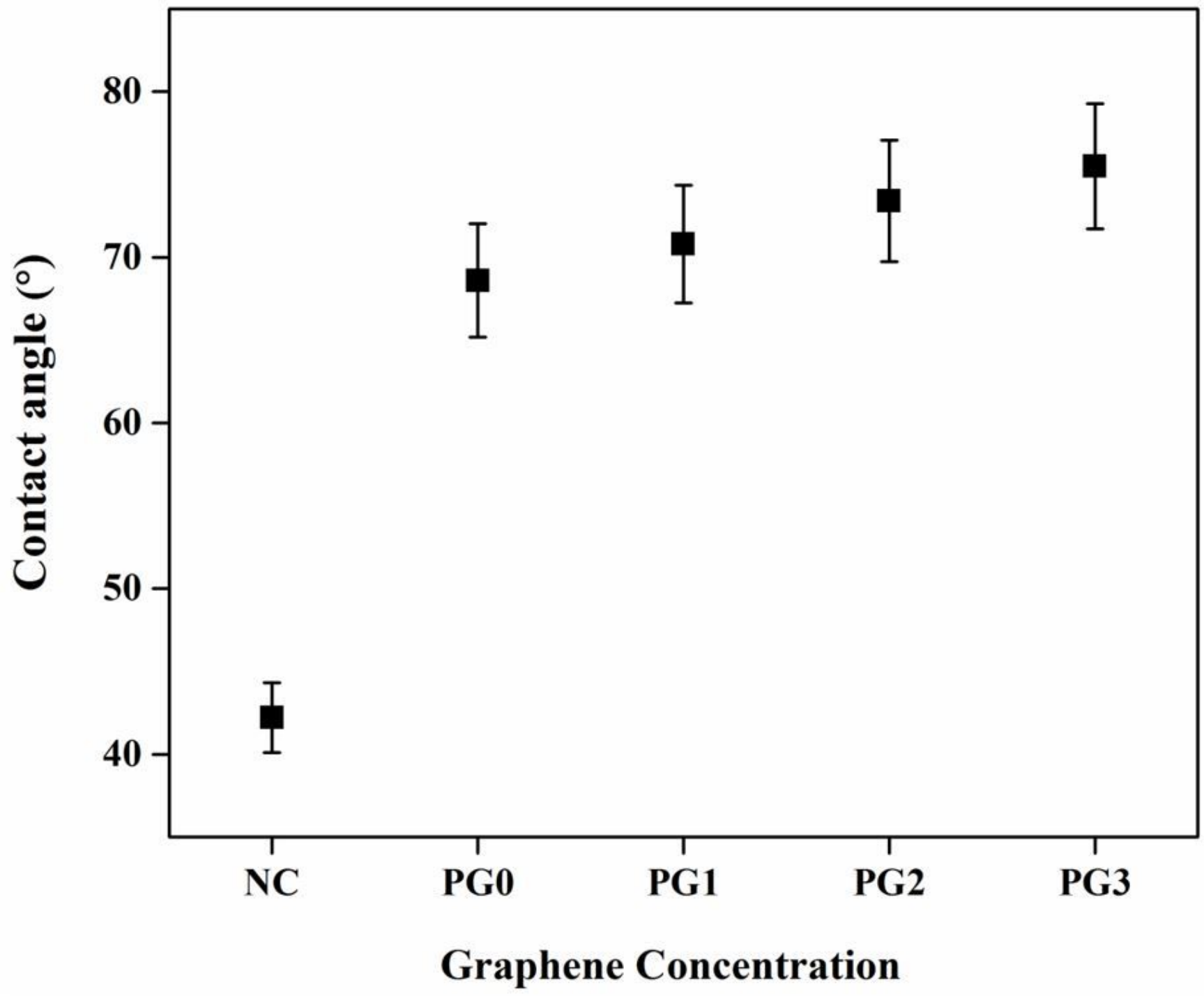

Figure 2

Contact angle of Pullulan/graphene bio nanocomposite coating 


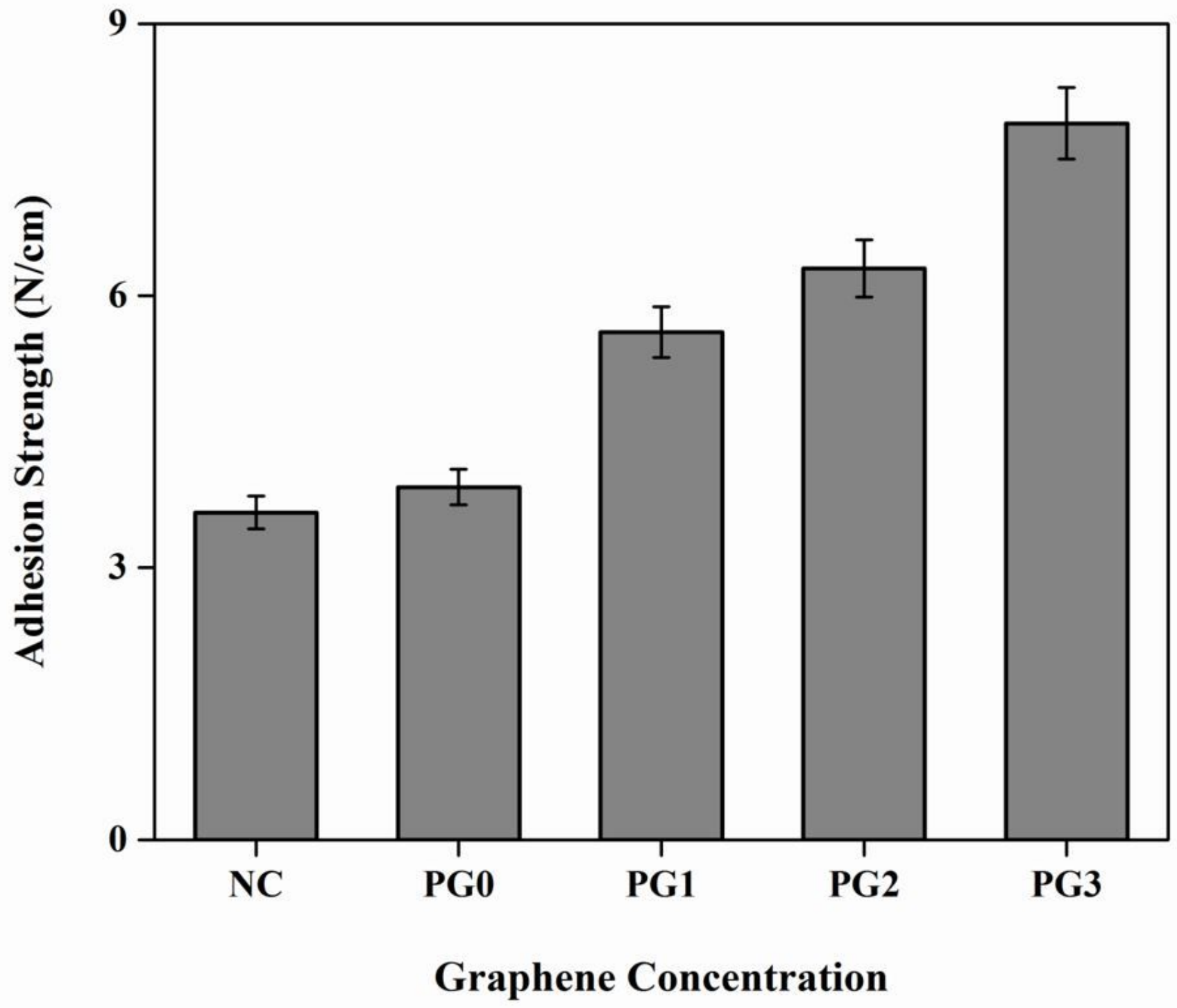

Figure 3

Adhesion strength of Pullulan/graphene bio nanocomposite coating 


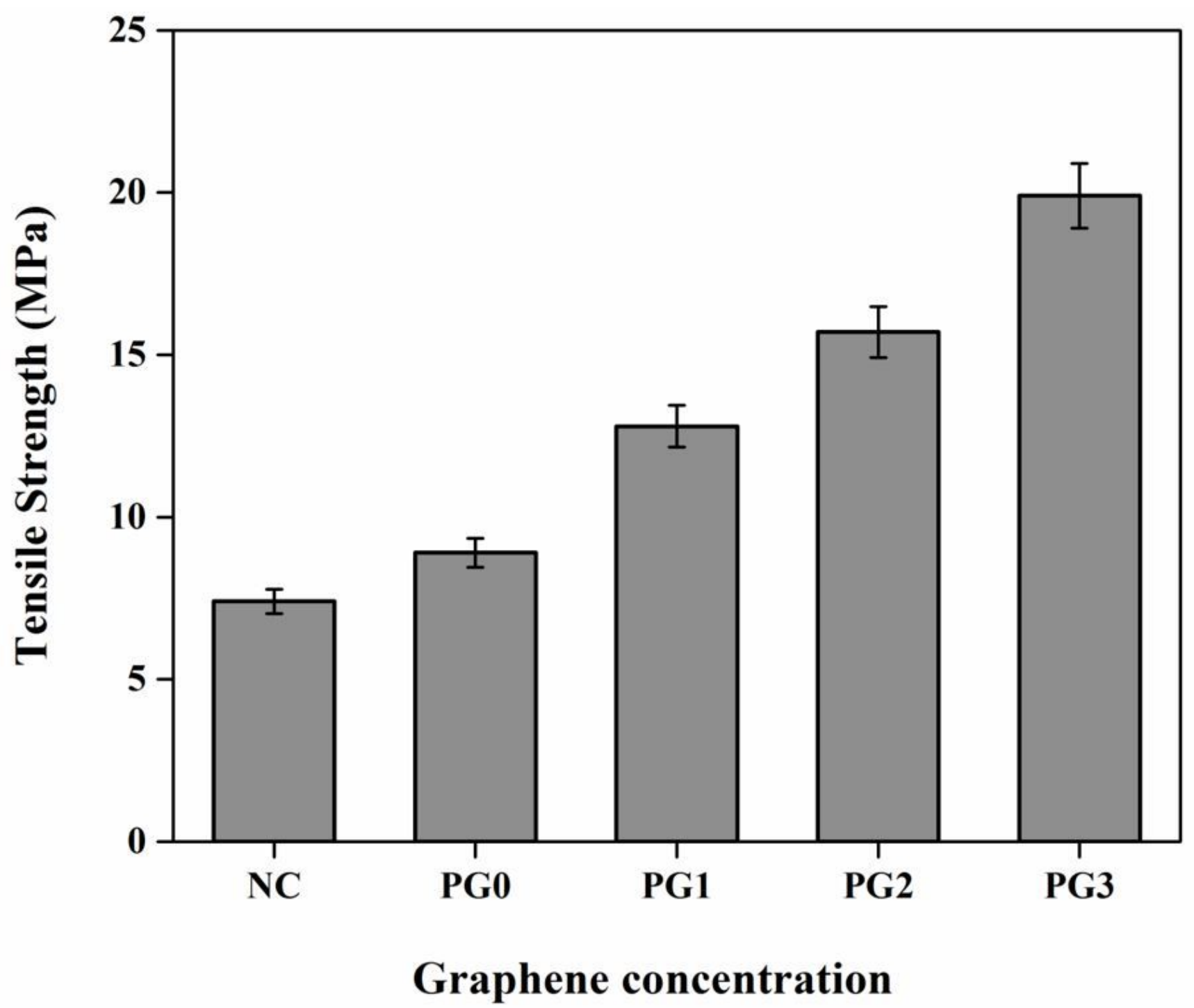

Figure 4

Tensile strength of Pullulan/graphene bio nanocomposite coating 


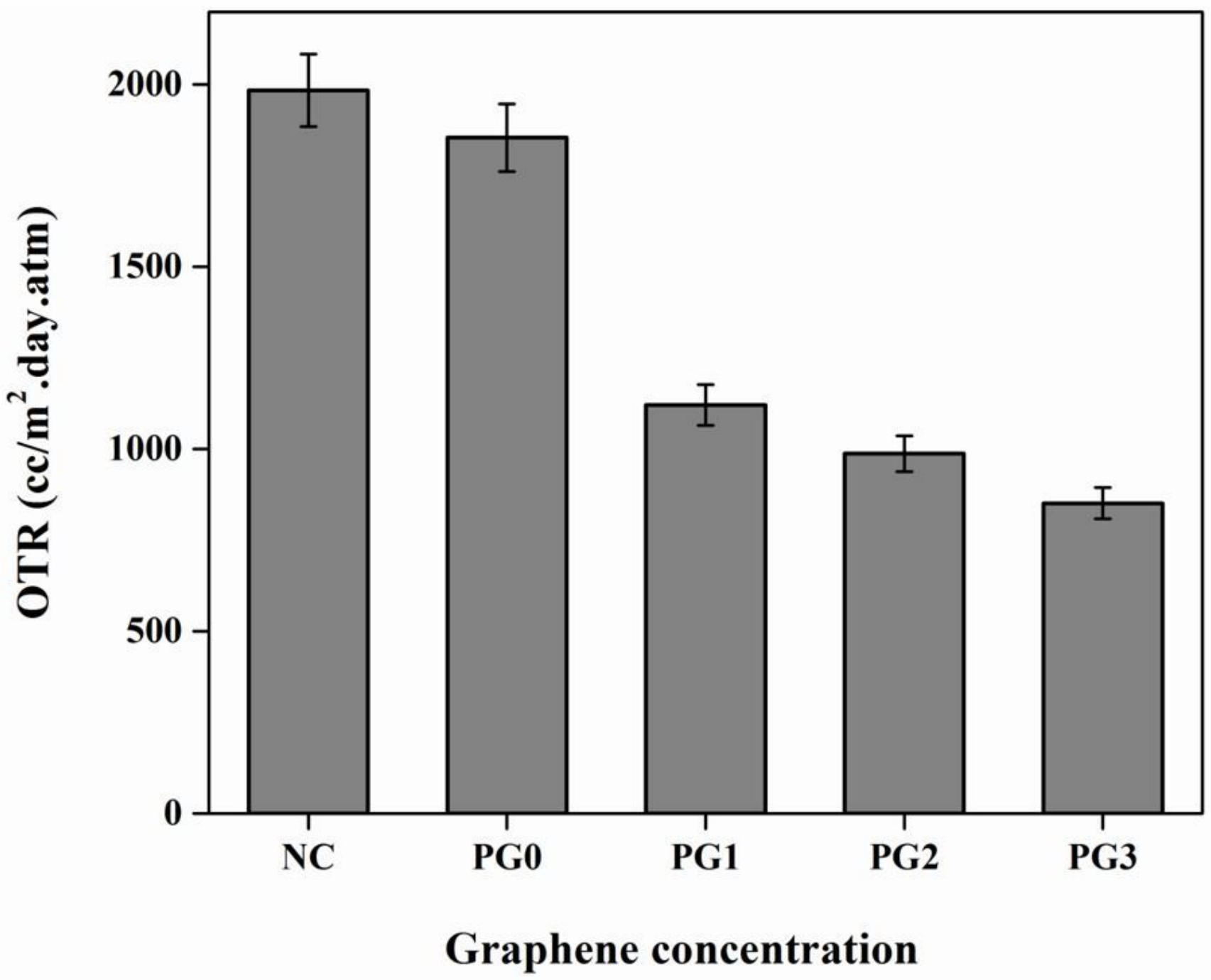

Figure 5

Oxygen transmission rate of Pullulan/graphene bio nanocomposite coating 


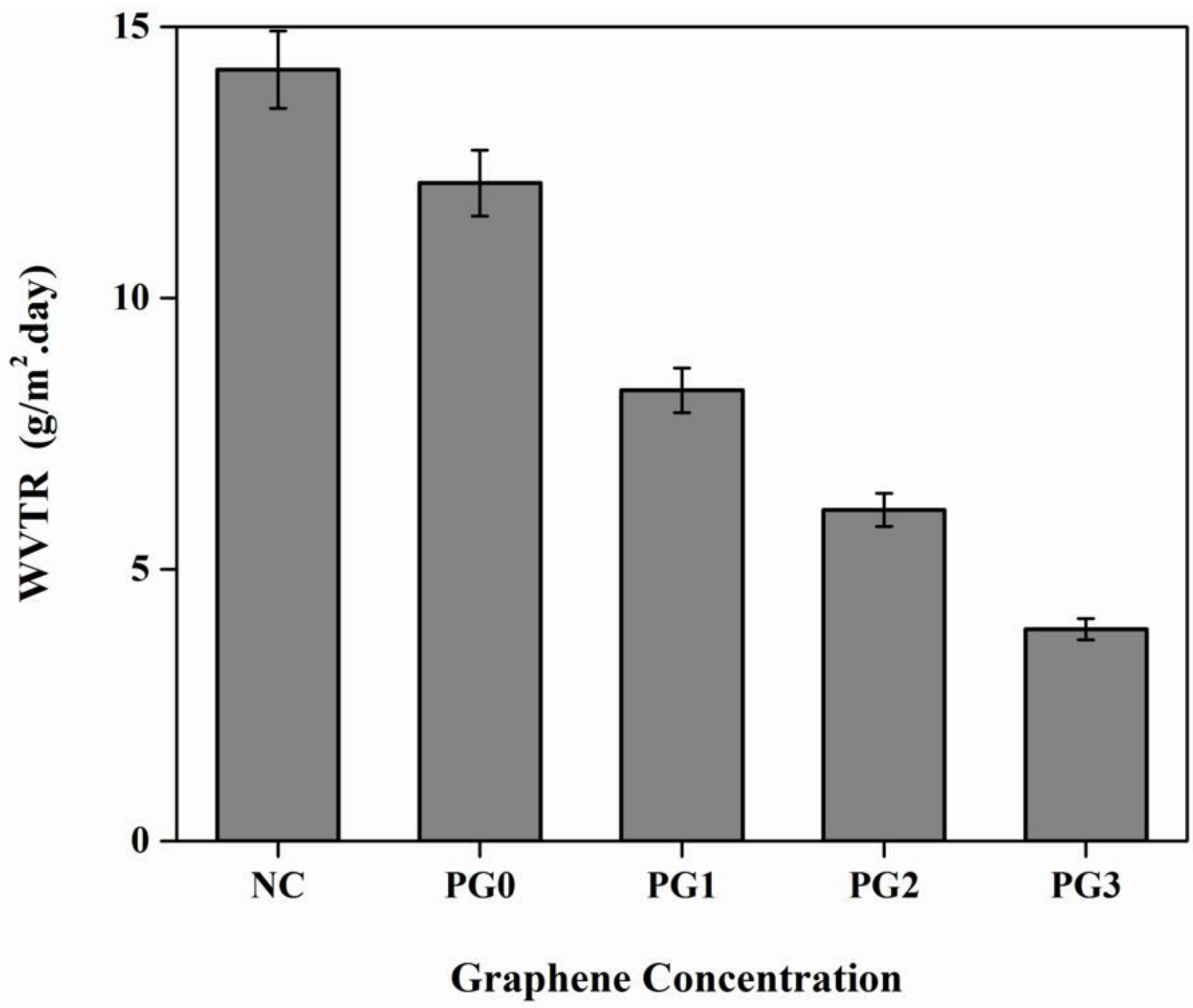

Figure 6

Watervapour transmission rate of Pullulan/graphene bio nanocomposite coating 


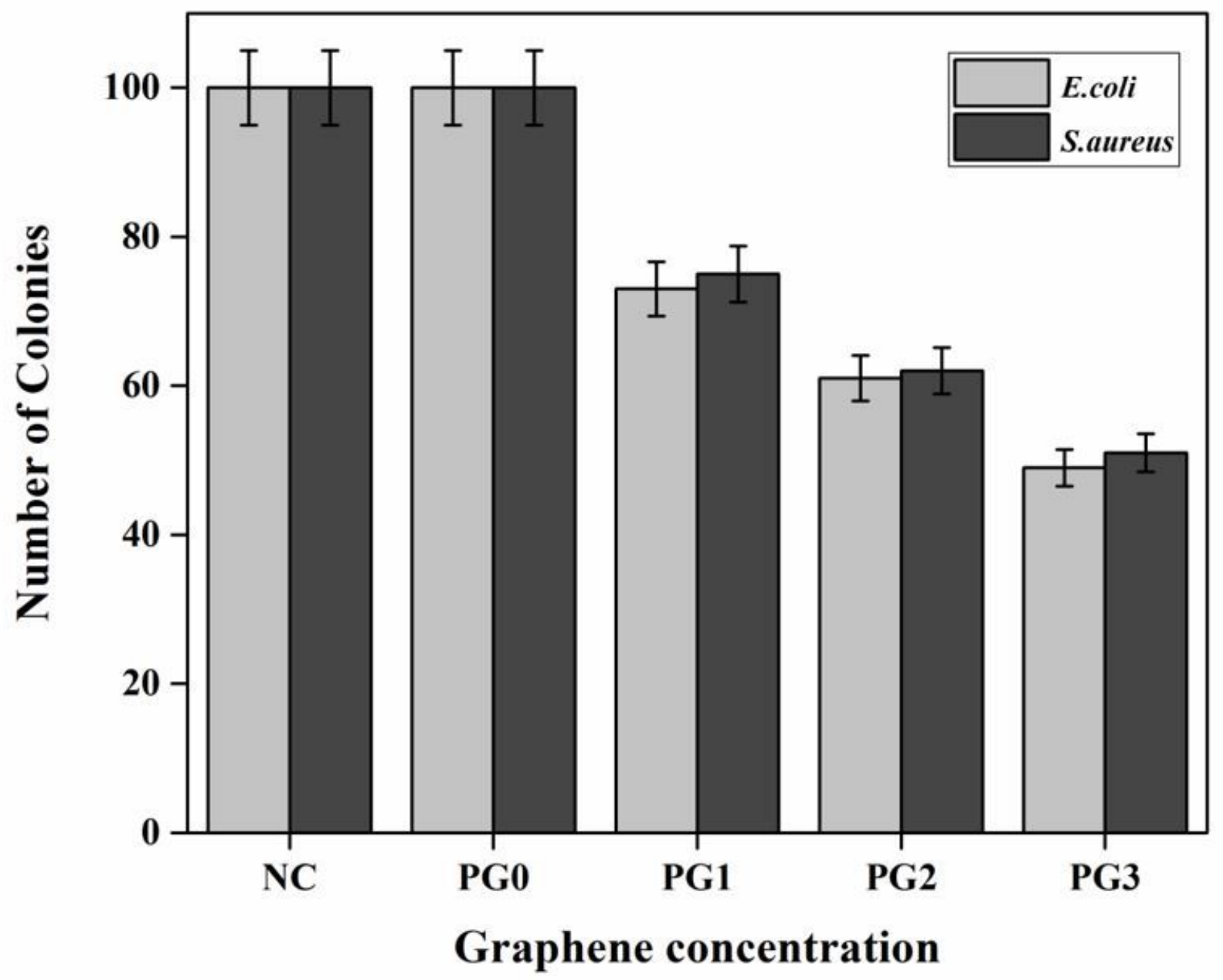

Figure 7

Antibacterial properties of Pullulan/graphene bio nanocomposite coating 